\title{
PROSESI PEMENTASAN DAN PERSEPSI MASYARAKAT LAMPUNG SELATAN TERHADAP BARONG KET DAN RANGDA DALAM UPACARA DEWA YAJNYA
}

\author{
Suyono $^{1}$, Iluh Kristiyanti \\ ${ }^{12}$ Sekolah Tinggi Agama Hindu (STAH) Lampung \\ 1ssuyono876@gmail.com
}

\begin{abstract}
Barong and Rangda dances are one of the art forms that exist in Balinese society. This dance is a traditional Balinese dance that uses a large animal mask with four legs. Barong and Rangda dance tells the story of the conflict between good and evil. The origins of Barong and Rangda are thought to have existed since the 16th century, during the reign of Dalem Waturunggung. This is indicated by the presence of Karang Bhoma, which is placed above the door or kori agung at the Paduraksa temple. In the form of barong and rangda, it seems that there is a mixture of Javanese artists with Balinese artists and has been influenced or inspired by Barongsae from China. In Sidowaluyo and Balinuraga villages, the Barong Ket and Rangda dances are performed at certain times, namely at large shrines at temples. However, not all people in the village know or understand the art of Barong Ket and Rangda and the reasons for their performance at the yajñ ceremony. The purpose of this study was to determine the performance procession and the perceptions of the people of South Lampung towards the performance of Barong Ket and Rangda in dewa yajñ ceremony.
\end{abstract}

\section{Keyword: Barong Ket dan Rangda, Lampung Selatan}

\begin{abstract}
Abstrak
Tarian Barong dan Rangda merupakan salah satu bentuk seni yang ada di masyarakat Bali. Tarian ini merupakan sebuah tari tradisional khas Bali yang menggunakan topeng hewan besar yang berkaki empat. Tari Barong dan Rangda bercerita tentang pertentangan antara kebaikan dan kejahatan. Asal-usul Barong dan Rangda diperkirakan sudah ada sejak abad 16, pada pemerintahan Dalem Waturunggung. Hal ini ditandai dengan adanya Karang Bhoma, ditempatkan di atas pintu atau kori agung pada Candi Paduraksa Pura. Wujud bentuk barong dan rangda ini nampak ada perpaduan antara seniman jawa dengan seniman Bali dan mendapat pengaruh atau inspirasi dari Barongsae dari Cina. Di Desa Sidowaluyo dan Desa Balinuraga, tari Barong Ket dan Rangda dipentaskan pada waktu tertentu, yaitu pada piodalan besar di Pura. Namun demikian, tidak semua masyarakat di desa tersebut mengetahui ataupun memahami seni Barong Ket dan Rangda serta alasan pementasannya pada upacara dewa Yajña. Tujuan penelitian ini adalah untuk mengetahui prosesi pementasan dan persepsi Masyarakat Lampung Selatan terhadap pementasan Barong Ket dan Rangda dalam upacara dewa yajña.
\end{abstract}

\section{Kata Kunci: Barong Ket dan Rangda, Lampung Selatan}

\section{Pendahuluan}

Dalam era globalisasi seperti sekarang ini, yang setiap harinya selalu mengalami perubahan, di dunia kebudayaan khususnya kesenian mengalami suatu perubahan - perubahan 
yang sangat menjolok utamanya dalam masalah aktivitas cipta, ide, dan penggarapan kesenian. Hal ini tentu saja membawa suatu dampak yang sangat besar terhadap perkembangan atau kehidupan kesenian khususnya pada masyarakat di Bali dan pada umumnya di Indonesia. Perkembangan ini tidak saja membawa suatu pengaruh yang positif, tetapi juga membawa pengaruh yang negatif. Penyebabnya bukan mutlak bersumber dari dunia kesenian, akan tetapi bersumber pada pengaruh global yang terjadi pada dunia modern ini. Karena pengaruh perubahan ini sangat berdampak pada semua sudut kehidupan, bahkan tidak tertutup kemungkinan bagi dunia kesenian. (Merlia, 2015)

Pulau Bali memang sudah terkenal ke seluruh dunia dengan kesenian dan budayanya. Dalam pelaksanaan upacara Dewa Yadnya, disamping mempergunakan sarana seperti banten, tabuh atau gamelan, kekidungan (seni suara), juga penting mempergunakan seni tari. Seni tari pada umumnya dapat dikategorikan menjadi tiga kelompok, yaitu wali atau seni tari yang bersifat sakral, bebali atau seni tari yang dipentaskan untuk mengiringi upacara-upacara, dan balih-balihan atau seni untuk hiburan. Tari sakral atau tari wali adalah tari yang dipentaskan dalam suatu rangkaian ritual-ritual atau yadnya pada saat tertentu dan tarian tersebut biasanya disucikan. Tari wali ini dipergunakan untuk pemujaan maupun sebagai pelengkap suatu pemujaan, salah satunya adalah tari barong ket dan rangda. (Sumadia, 2011)

Tarian Barong merupakan salah satu bentuk seni masyarakat dari begitu banyak bentuk seni yang ada di Bali. Tarian ini adalah sebuah tari tradisional khas Bali yang ditandai dengan adanya topeng hewan berkaki empat yang besar. Tari Barong bercerita tentang pertentangan antara kebaikan dan kejahatan. Ada banyak cerita mengenai sejarah Tari Barong yang ada di Bali dipercaya sebagai metamorfosis dari Barong Ponorogo atau Reog, oleh raja Airlangga saat mengungsi ke pulau Bali untuk menyelamatkan diri. Dalam perkembangannya Barong Ponorogo di rubah bentuk dan cerita sesuai kondisi masyarakat di bali yang diperuntukan untuk kegiatan spiritual keagamaan. Tari Barong ini dianggap kesenian yang sakral sehingga terdapat juga kesan mistis di dalamnya. Tari Barong ini selain sifatnya yang sakral juga bisa menjadi hiburan bagi masyarakat. Untuk Tari Barong yang ditampilkan sebagai bagian dari upacara di Pura, biasanya dilakukan dengan serius. Karena berhubungan dengan makna spiritual yang ada sehingga dilakukan secara sakral. Sedangkan Tari Barong yang ditampilkan untuk hiburan, biasanya diselingi dengan adegan-adegan yang lucu. Selain itu ada juga penampilan atraktif dari penari seperti pertunjukan ilmu kekebalan yang membuat decak kagum para penonton. Pertunjukan tari barong ket ini biasanya ditampilkan dengan selingan unsur humor yang dapat membuat penonton terhibur. (longtripmania. 2014)

Dalam Lontar Siva Tattwa menceritakan Sang Hyang Siva turun ke bumi pada sasih kalima. Sebelum itu saktinya dewi Durga telah turun terlebih dahulu dengan berwujud Rangda dengan gelar Sang Hyang Barawi beserta pengiringnya Buta Kala dan Pemali. Karena dikatakan istrinya salah wetu maka Sang Hyang Siwa pun turun kebumi dengan membawa wujud bhuta egeg seperti Banaspati Raja yang menyerupai Barong. Atas rasa hormat dan hasrat menjunjung tinggi Banaspati Raja sebagai salah satu murti (perwujudan) Sang Hyang Siwa, maka atas petunjuk gaib yang diterima oleh umat Hindu diberbagai tempat di Bali, maka dibuatlah tiruan wujud fisiknya dalam bentuk topeng dan difungsikan sebagai simbul keagamaan. Apapun jenis atau sebutan Barong baik Ratu Bagus, Ratu Gede dan yang lainnya pasti masyarakat meyakini bahwa spirit dari Barong adalah Ida Bhatara Dalem yang tiada lain Murti/citra dan manifestasi dari Sang Hyang Siwa. (Wirawan. 2016:6.7)

Tari sakral adalah sebuah tarian tradisional yang dipentaskan di bagian halaman dalam sebuah pura, pada areal sebuah pura biasanya terdiri dari 3 bagian halaman yaitu bagian halaman luar, tengah dan dalam. Dan dalam hal ini tari sakral tersebut dipentaskan di bagian dalam pada bagian paling utama pada sebuah halaman pura, dan pementasan tersebutpun tidak sembarang, karena berhubungan dengan upacara yadnya. Perlu diketahui di Bali sendiri ada beberapa jenis tari tradisional Bali yang dipentaskan pada sebuah Pura, diantaranya adalah tari 
Wali atau tari sakral dipentaskan di jeroan (halaman utama) Pura, tari tradisional Bebali atau tarian untuk upacara dipentaskan di Jaba Tengah (halaman tengah) pura dan tari Balih-balihan sebuah tarian yang dipentaskan untuk tujuan menghibur, tari ini dipentaskan pada bagian (Jaba Jero) halaman luar Pura. Barong ket dan rangda dikatakan sakral karena melalui beberapa proses sakralisasi, tahapannya melalui tiga tingkatan yakni tingkat Prayascitta, pasupati/ngatep dan ngerehin.

Apabila makna dalam sebuah tari sakral belum difahami oleh masyarakat, maka upacara yajna yang menampilkan tarian sakral seperti Barong Ket dan Rangda tidak akan terasa sempurna karena masyarakat belum memahami apa, bagaimana dan mengapa tari barong ket dan rangda ada dan ditarikan dalam upacara yajna. Berdasarkan uraian di atas, penulis tertarik untuk meneliti tentang tari barong ket dan rangda dengan judul: Prosesi Pementasan dan Persepsi Masyarakat Terhadap Pementasan Barong Ket dan Rangda di Lampung Selatan Dalam Upacara Dewa Yajña.

\section{Metode}

Penelitian dilaksanakan di dua tempat yaitu di Desa Sidowaluyo, Kecamatan Sidomulyo dan di Desa Balinuraga, Kecamatan Way Panji, Kabupaten Lampung Selatan dengan sasaran penelitian tertuju pada masyarakat Hindu. Metode yang digunakan dalam penelitian ini adalah metode kunatitatif. Penggunaan metode kuantitatif dimaksudkan untuk memperoleh gambaran yang jelas tentang suatu permasalahan yang sedang terjadi dengan cara mengolah, menganalisis, menafsirkan dan menyimpulkan data berupa angka-angka dari hasil penelitian. Permasalahan yang akan dikaji dalam penelitian ini yaitu Prosesi pementasan dan persepsi masyarakat terhadap Barong Ket dan Rangda di Lampung Selatan dalam upacara Dewa Yajna. Teknik pengumpulan data yang digunakan dalam penelitian ini adalah metode observasi, observasi ini dilakukan untuk mengetahui secara langsung bagaimana prosesi/runtutan acara yang dilakukan dari sebelum pementasan barong ket dan randa, sampai pementaan selesai. Prosesi pementasan Barong Ket dan Rangda pada rahinan tumpek landep di desa Balinuraga Sabtu, 25 Mei 2019 terdapat tiga tahap yang pertama H-1 atau satu hari sebelum Barong Ket dan Rangda dipentaskan, kedua pada saat pementasan Barong Ket dan Rangda, dan yang ketiga pada saat selesai pementasan. Tahap pertama disebut dengan Mendak/Ngebeji (mungkah lawang/membuka pintu kemudian menghaturkan segehan manca warna, setelah itu rambut pralingga Barong ket dan Rangde dihiasi dengan bunga kamboja agar terlihat indah, kemudian dilakukan upacara Durmanggala, Pebiekaonan, Pengulap, Prayascita tujuannya untuk membersihkan pralingga Barong dan Rangda sebelum di Stanakannya Sang Hyang Siva. Tahap kedua pada hari H Jro Mangku akan menghaturkan pejatian dan segehan manca warna kehadapan Sang Hyang Pencipta untuk memohon izin dan menjadi saksi bahwa akan diadakannya pementasan Barong Ket dan Rangda. Tahap akhir selesai dipentaskan barulah barong ket dikembalikan pada tempat semula. Metode observasi terstruktur dimaksudkan agar dalam mengadakan penelitian ini melalui pengamatan dan pencacatan secara sistematis, dengan pengamatan dan pencatatan yang dimaksud untuk memperoleh gambaran yang lebih jelas dan diharapkan mendapatkan data yang lebih akurat mengenai "Prosesi Pementasan dan Persepsi Masyarakat Terhadap Pementasan Barong Ket di Lampung Selatan dan Rangda dalam upacara Dewa Yajnya".

Wawancara dilakukan untuk mendapatkan informasi mengenai prosesi dan pementasan barong ket dan rangda secara langsung, agar informasi yang didapat oleh peneliti menjadi relevan sesuai dengan yang sebenarnya. Orang yang dapat memberikan informasi mengenai Barong Ket dan Rangda yaitu wawancara kepada Wayan Mantre, Made Suaste dan Made Suastanaya selaku lakon atau pemeran tarian Barong dan Rangda, dan wawan cara juga dilakukan kepada Sri Mpu Darma Putra Giridwaja. Kuesioner adalah teknik pengumpulan data yang dilakukan dengan cara memberi seperangkat pertanyaan dan pernyataan tertulis pada 
responden untuk menjawab. Dalam angket terdapat beberapa pertanyaan, dalam pertanyaan itu memiliki jawaban yang berisi bobot, yang berjumlah 5 buah dan memiliki skor masing-masing. Skor dari masing masing jawaban adalah Sangat setuju dengan skor 5, Setuju skor 4, raguragu skor 3, tidak setuju skor 2, dan sangat tidak setuju skor 1.

Dalam penelitian angket dapat dijadikan acuan dalam proses pengumpulan data, angket juga dapat membantu peneliti untuk menghemat waktu, biaya dan tenaga. Dalam penelitian ini questioner/angket diberikan kepada 60 orang pemuda yang usianya 18-45 tahun dan 60 orang tua yang usianya diatas 46 tahun.

\section{Hasil dan Pembahasan}

Prosesi pementasan Barong Ket dan Rangda terdapat dua tahap yang pertama H-1 atau satu hari sebelum Barong Ket dan Rangda dipentaskan, kedua pada saat pementasan dan ketiga penutup. Tahap pertama disebut dengan Mendak/Ngebeji (mungkah lawang/membuka pintu kemudian dilakukan menghaturkan segehan manca warna kemudian pralingga Barong dan Rangda dikeluarkan dari tempat penyimpanannya setelah itu rambut pralingga dihiasi dengan bunga kamboja agar terlihat indah, selanjutnya menghaturkan Banten Durmanggala, Pebiekaona, pengulap dan Prayascita tujuannya untuk membersihkan Pralingga Barong dan Rangda sebelum di Stanakannya Sang Hyang Siva, Tahap kedua pada hari H Jro Mangku akan menghaturkan Pejatian dan segehan kehadapan Sang Hyang Pencipta untuk memohon izin dan menjadi saksi bahwa akan diadakannya upacara yadnya dan pementasan Barong Ket dan Rangda tujuannya agar tidak terjadi hal-hal yang tidak dinginkan. Tahap ketiga yaitu penutup, setelah selesai dipentaskan masyarakat akan melakukan persembahyangan bersama kemudian setelah itu pralingga pun akan dikembalikan pada tempat semula, sebelum itu dilakukan upacara menghaturkan Segehan tujuannya untuk menetralisir dan mengembalikan Sang Hyang Siva yang telah Berstana pada Pralingga Barong dan Rangda kembali kealam Svah.

Hasil analisis data mengenai partisipasi langsung antara orang tua dan anak muda disajikan pada Tabel 1.

Table 1 Persepsi Masyarakat Terhadap Partisipasi Langsung

\begin{tabular}{|c|c|c|c|c|c|c|c|}
\hline Variabel & Indikator & $\begin{array}{c}\text { Orang } \\
\text { Tua }\end{array}$ & $\begin{array}{c}\text { Anak } \\
\text { Muda }\end{array}$ & $\begin{array}{c}\mathbf{t} \\
\text { Hitung }\end{array}$ & $\begin{array}{c}\mathbf{t} \\
\text { Tabel }\end{array}$ & $\mathbf{P}(\mathbf{t}<=\mathbf{t})$ & Ket \\
\hline $\begin{array}{c}\text { Partisipasi } \\
\text { Langsung }\end{array}$ & Pengetahuan & 4.09 & 4.01 & 0,67 & 1,98 & 0,49 & $\begin{array}{c}\text { Tidak } \\
\text { Berbeda }\end{array}$ \\
\hline & Ide & 4.75 & 4.55 & 2,16 & 1,98 & 0,03 & Berbeda \\
\hline & Pemahaman & 4.65 & 4.51 & 1,01 & 1,98 & 0,31 & $\begin{array}{c}\text { Tidak } \\
\text { Berbeda }\end{array}$ \\
\hline & Fisik & 4.65 & 4,61 & 0,33 & 1,98 & 0,74 & $\begin{array}{c}\text { Tidak } \\
\text { Berbeda }\end{array}$ \\
\hline & 4.53 & 4.42 & 1,34 & 1,98 & 0,18 & $\begin{array}{c}\text { Tidak } \\
\text { Berbeda }\end{array}$ \\
\hline
\end{tabular}

Pada tabel 1 tersebut tampak bahwa partisipasi langsung secara umum orang tua memiliki skor 4.53 dan anak muda skor 4.42. Nilai skor tersebut mendekati nilai sangat baik yang artinya mereka sama-sama berpartisipasi dan mendukung adanya pementasan Barong Ket dan Rangda didesanya dalam upacara dewa yajnya. Partisipasi langsung untuk pengetahuan untuk orang tua memiliki skor 4.09 dan anak muda skor 4.01 bagus dan tidak berbeda. Berdasarkan uji t partisipasi langsung terhadap ide untuk orang tua memiliki skor 4.75 dan anak muda skor 4.55 berbeda. Partisipasi langsung terhadap pemahaman untuk orang tua memiliki skor 4.65 dan anak muda skor 4.51 tidak berbeda. Partisipasi langsung terhadap fisik untuk orang tua memiliki skor 4.65 dan anak muda skor 4.61tidak berbeda. 
Hasil analisis data mengenai partisipasi langsung antara orang tua dan anak muda disajikan pada Tabel 2 .

Table 2. Persepsi Masyarakat Terhadap Partisipasi Tidak Langsung.

\begin{tabular}{|c|c|c|c|c|c|c|c|}
\hline Variabel & Indikator & $\begin{array}{c}\text { Orang } \\
\text { Tua }\end{array}$ & $\begin{array}{c}\text { Anak } \\
\text { Muda }\end{array}$ & $\begin{array}{c}\mathbf{t} \\
\text { Hitung }\end{array}$ & $\begin{array}{c}\mathbf{t} \\
\text { Tabel }\end{array}$ & $\mathbf{P}(\mathbf{t}<=\mathbf{t})$ & Ket \\
\hline $\begin{array}{c}\text { Partisipasi } \\
\text { Tidak } \\
\text { Langsung }\end{array}$ & $\begin{array}{c}\text { Dukungan } \\
\text { Orang Tua }\end{array}$ & 5 & 4,68 & 0,62 & 2 & 0,53 & $\begin{array}{c}\text { Tidak } \\
\text { Berbeda }\end{array}$ \\
\hline & $\begin{array}{c}\text { Minat } \\
\text { Anak }\end{array}$ & 4,63 & 4.7 & 0,67 & 1,98 & 0,50 & $\begin{array}{c}\text { Tidak } \\
\text { Berbeda }\end{array}$ \\
\hline & General & 4.65 & 4.69 & 0,39 & 1,98 & 0,69 & $\begin{array}{c}\text { Tidak } \\
\text { Berbeda }\end{array}$ \\
\hline
\end{tabular}

Pada tabel 2 tersebut tampak bahwa partisipasi tidak langsung secara umum antara orang tua 4.65 dan anak muda 4.69. Nilai skor tersebut mendekati nilai sangat baik yang artinya dengan keberadaan seni tari ini dapat memberikan nilai positif bagi penerus generasi muda Hindu di desannya. Partisipasi tidak langsung dukungan orang tua untuk orang tua memiliki skor 5 dan anak muda skor 4.68 bagus/baik dan tidak berbeda. Partisipasi tidak langsung minat anak tua untuk orang tua memiliki skor 4.63 dan anak muda skor 4.7 bagus dan tidak berbeda.

\section{Kesimpulan}

Hasil analisis data mengenai partisipasi langsung dan partisipasi tidak langsung antara orang tua dan anak muda terhadap Barong Ket dan Rangda tidak berbeda yakni setuju apabila selalu diadakannya pementasan barong ket dan rangda pada Piodalan besar di Pura. Adanya kesenian ini juga dianggap sangat memberi pengaruh positif pada generasi muda agar bisa melestarikan seni dan budaya peninggalan leluhur, yang artinya masyarakat juga berkerja sama dengan anak muda untuk saling menjaga dan melestarikan seni budaya bali agar tetep ajeg. Diharapkan bagi para orang tua untuk selalu mendukung setiap kegiatan yang dinilai positif bagi anak muda terutama dalam kegiatan untuk melestarikan kesenian bali dan tradisi leluhur. Anak muda juga diharapkan dapat meneruskan dan menjalin kebersamaan agar tradisi dan budaya terutama kesenian Barong Ket dan Rangda tetap ajek dan lestari.

\section{Daftar Pustaka}

Ari Santi, N. K. (2013). Menguak Misteri Pementasan Barong Ket Dan Rangda Dari Sudut Pandang Sains (Cosmics Fertilization). Surabaya: Paramita

Dibia, I W. (2018). Tari Barong Ket Dari Kebangkitan Menuju Kejayaan. Denpasar: Cakra Media Utama

Sugiono. (2017). Metode Penelitian Pendidikan (Pendekatan Kuantitatif, Kualitatif dan $R \&$ $D)$; Alfabeta. Bandung

Sugiono. (2017). Statistika Untuk Penelitian; Alfabeta. Bandung

Veronikawati, M. (2018). Persepsi Berbagai Strata Social Masyarakat Di Kecamatan Seputih Mataram Lampung Tengah Terhadap Kebijakan Pembangunan Pasraman Formal. Bandar Lampung. STAH Lampung

Wirawan, K. I. (2016). Keberadaan Barong Ket Dan Rangda Dalam Dinamika Religious Masyarakat Hindu Bali. Surabaya: Paramita

Asmoro, B. (2018). Persepsi Masyarakat Di Kecamatan Seputih Mataram Kabupaten Lampung Tengah Terhadap Aktivitas Keagamaan Alumni STAH Lampung. Bandar Lampung. STAH Lampung

Pratiwi, G. A. K, T. (2016). Nilai-Nilai Sacral Tari Gambyong Dalam Pelaksanaan Upacara Dewa Yajna. Bandar Lampung. STAH Lampung. 
Purnama Dewi, N. N. M. (2014). Nilai-Nilai Sakral Tari Bedayo Tulang Bawang Dalam Mendukung Pelaksanaan Pujawali. Bandar Lampung. STAH Lampung.

Sumantara, I N. G. (2010). Makna Kawangen Dalam Pelaksanaan Persembahyangan Kramaning Sembah Yang Dilakukan Oleh Umat Hindu. Bandar Lampung. UNHI Denpasar

Sumaja, I W. (2007). Pralingga Barong Ket Dan Rangda Dalam Tradisi Keagamaan Masyarakat Hindu Di Desa Balinuraga Kecamatan Way Panji Lampung Selatan. Bandar Lampung. STAHDN Jakarta

Azzamiaandaru. (2017). pementasan tari. https://brainly.co.id/tugas/339586/. Diakses 21 Mei 2019

Biakta, I. B. (2015). Banten Prayascitta Dalam Upacara Dewa Yadnya Di Pura Penataran Agung (Ditinjau Dari Bentuk, Fungsi Dan Makna) http://biakt4.blogspot.com/2015/02/banten-prayascita-dalam-upacara-dewa.html/. Diakses 10 februari 2015

KBBI. (2019). Prosesi. https://id.wikipedia.org/wiki/Prosesi/. diakses 31 juli 2019.

Longtripmania. (2014). Tari bali. https://www.longtripmania.org/2016/02/tari-barong-ketatau-barong-keket.html/. diakses 15 mei 2019.

Merlia, Mei. (2015). Seni sacral. http://catatankampus.wordpress.com/2015/01/16/senisakral/. Diakses 01 Agustus 2019.

Rulita. (2017). Seni pertunjukan. https://ilmuseni.com/seni-pertunjukan/pengertian-senipertunjukan-menurut-para-ahli/. diakses 15 Mei 2019

Sumadia, K. (2011). Proposal Penelitian Pementasan Tari Rejang Renteng Dalam Rangka Piodalan Agung Di Pura Desa Pakraman Sukasada Kecamatan Sukasada, Kabupaten Buleleng. https://www.academia.edu/5383433/PROPOSAL_PENELITIAN/. Diakses 01 agustus 2019.

Umi Ningrum, I. A. L. dkk (2017). Pemujaan Ida Bhatara Ratu Gede Di Pura Jati Desa Pakraman Keranjangan Desa Manukaya Kecamatan Tampaksiring. Institut Hindu Dharma Negeri Denpasar. https://studylibid.com/doc/988858/pemujaan-ida-bhatararatu-gede-di-pura-jati-desa/. Diakses 01 Agustus 2019 